\title{
A Distributed Exergame for Telerehabilitation: An Engaging Alternative to Improve Patients' Quality of Life
}

\author{
CARLOS HENRIQUE RORATO SOUZA, DANIEL MACHADO DE OLIVEIRA, \\ LUCIANA DE OLIVEIRA BERRETTA, SÉRGIO TEIXEIRA DE CARVALHO,
}

Institute of Informatics, Federal University of Goiás, Brazil.

\begin{abstract}
There are many factors that have a direct impact on the effectiveness of rehabilitation sessions. Among the main ones are: the availability of treatment, the active participation of the physiotherapist and the patient's motivation and engagement in performing the exercises. In this sense, this project presents the construction of a distributed exergame that, using equipment and sensors coupled to the cycle ergometer (device used in the activity), aims to allow telerehabilitation sessions, where the patient and physiotherapist are in their respective houses, and perform these activities in a less boring and more engaging way, increasing the patient's quality of life.
\end{abstract}

CCS Concepts: • Applied computing $\rightarrow$ Health informatics.

Additional Key Words and Phrases: games, exergames, rehabilitation, telerehabilitation, engagement, healthcare

\section{ACM Reference Format:}

Carlos Henrique Rorato Souza, Daniel Machado de Oliveira, Luciana de Oliveira Berretta, Sérgio Teixeira de Carvalho. 2021. A Distributed Exergame for Telerehabilitation: An Engaging Alternative to Improve Patients' Quality of Life. In LIQUE 2021: Life Improvement in Quality by Ubiquitous Experiences Workshop, together with IMX 2021: ACM International Conference on Interactive Media Experiences, June 21-23, 2021, NY, USA.

\section{INTRODUCTION}

Patient rehabilitation is a sort of healthcare that presents several questions and variables on which its effectiveness depends [9]. We consider the following factors:

- The availability of treatment, which involves the presence of the health professional, the equipment and the possibility of patients' displacement to where the sessions are held. Many patients' access to therapy is hampered by many factors, either because they live in distant environments (rural, for example), or other adverse reasons, such as the reality of social distance imposed by COVID-19 [3].

- The active participation of the physiotherapist is an extremely important factor for the patient to perform correctly the exercises and for his health status to be monitored and the activities regulated [1]. With access difficulties, this participation is restricted and often does not happen. In many places, the solution found consists in the elaboration of teaching materials, such as explanatory booklets, which are provided to the patient [2].

- The patient's motivation and engagement in the exercises being performed [5]. Often, the activities are repetitive and boring, making the patient not perform the exercises or do them inappropriately. Without engagement, rehabilitation cannot achieve the expected results. The engagement is crucial to the quality of life of patients, especially those who need to perform rehabilitation exercises for long periods.

Published in accordance with the terms of the Creative Commons Attribution 4.0 International Public License (CC BY 4.0). Permission to reproduce or distribute this work, in part or in whole, verbatim, adapted, or remixed, is granted without fee, provided that the appropriate credits are given to the original work, not implying any endorsement by the authors or by SBC.

(C) 2021 Brazilian Computing Society. 
Considering the telerehabilitation scenario in which patient and physiotherapist are in different places (for example, each one in their home) and the session is mediated by means of communication [7], the problems add up and intensify. The lack of active participation by the physiotherapist, the difficulties in monitoring the activity and the lack of motivation and engagement become major obstacles that can hinder the effectiveness of the sessions.

In this context, this project presents an exergame, which is a serious game that aims to make the practice of physical exercises less boring and more motivating [4], by promoting the patient's engagement with the game. Our game aims to help telerehabilitation sessions that use the cycle ergometer as a device, which is transformed into a low-cost "joystick" through the coupling of sensors to capture the patient's vital data and pedaling, being a low cost alternative. A magnetic switch (for counting the pedaling of the cycle ergometer) and a heart rate and blood oxygen saturation (oxymetry) sensor (MAX30102 ${ }^{1}$ ) is attached to an Arduino board (Figure 1). The data are sent to the computer via the serial port from Arduino, which builds a JSON (JavaScript Object Notation) tuple to send the data [8].

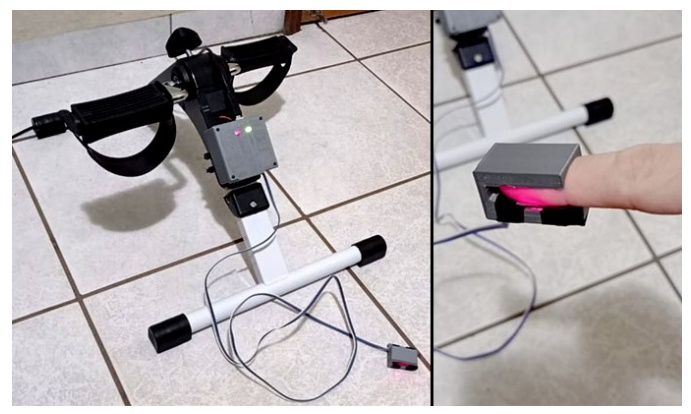

Fig. 1. The adapted cycle ergometer.

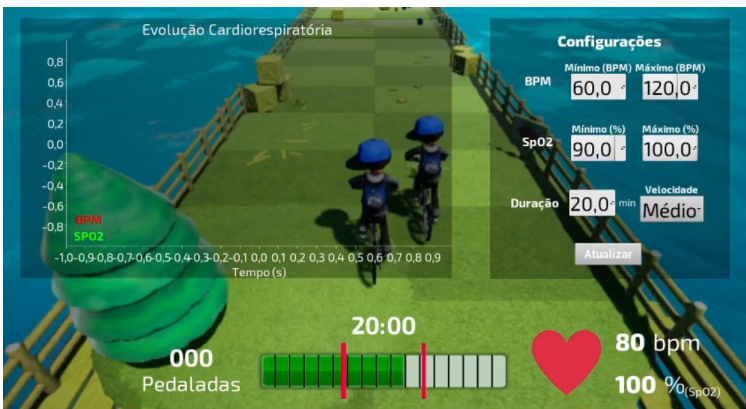

Fig. 2. Physiotherapist's screen in the "player" mode.

The game, which design is based on the endless runner model, presents an avatar with a bicycle controlled by the patients' pedaling on the cycle ergometer and an auxiliary joystick that allows more movements. The goal is to collect as many coins as possible throughout the race, avoiding obstacles, within the time stipulated by the physiotherapist. Vital patient data and other information are shown on the patient and healthcare professional's screen in real time, using real-time system techniques. In addition, the solution allows for audio and video communication, through an embedded video call implementation.

\section{THE EXERGAME - SOME DETAILS}

The game was developed in a distributed architecture as a multiplayer, with each actor (patient and physiotherapist) being a player, even though they perform different functions. Unreal Engine $4^{2}$ was chosen because its support for multiplayer applications and client-server architecture. The server can be run on one of the hosts (patient or physiotherapist) or in a dedicated way. Communication occurs by storing information and requesting it between the clients and the server. Unreal Engine has a real-time system that allows this implementation ${ }^{3}$.

Therefore, the data from the sensors that are stored in variables within the Patient player are sent to the server and will be available to the physiotherapist, who will request access. On the other hand, the exergame configuration data, provided by the physiotherapist, are also sent to the server and the Patient, in turn, will make the request before the activity starts or when these settings are changed by the Physiotherapist.

\footnotetext{
${ }^{1}$ www.maximintegrated.com

${ }^{2}$ www.unrealengine.com

${ }^{3}$ https://docs.unrealengine.com/en-US/InteractiveExperiences/Networking/index.html
} 
Before the activity starts, it needs to be configured by both actors. The patient, on his screen, needs to indicate in which serial port the cycle ergometer is connected and the Physiotherapist, in turn, makes the configuration of the activity parameters, such as the expected speed, the duration and the minimum and maximum values expected in the heart rate values. and blood oxygen saturation.

The configuration, however, allows other adjustments that aim to provide a greater degree of personalization of the activity, making the session to be tailored, considering the needs of each patient. In this sense, the Physiotherapist can configure the presence or absence of obstacles (from which the patient must avoid) or coins (objects that the patient must collect). He can also choose how he prefers to participate in the experience, either as a spectator (without interacting directly with the game, just monitoring the information) or as a player (participating in the activity with an avatar next to the patient's avatar). When the two actors are ready to start the activity, each one must press the "Play" button. This synchronizes the beginning of the activity, like a "handshake".

When starting the activity, the exergame presents a character who, using a bicycle, rides at the speed corresponding to that of the patient. A green bar displayed on the screen will increase your count with each new cycle of the pedal and the value of this increase will be proportional to the time of the last cycle. Thus, the player must be aware of his speed to maintain the bar mark between the two red bands, which will show the minimum and maximum margins defined by the physiotherapist.

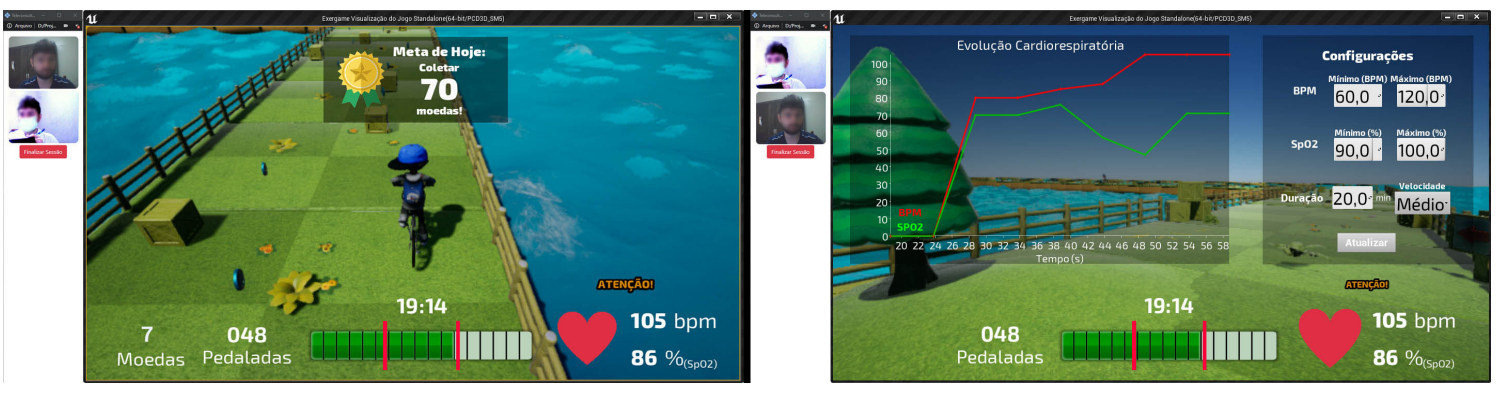

Fig. 3. Patient's screen (left) and physiotherapist's screen (right).

Boxes are generated at random points to be obstacles, in addition to coins and objects to be collected by the character. The goal is to end the activity by pedaling at a speed within the range indicated by the physiotherapist, collecting as many coins as possible and avoiding obstacles. For each game, a coin collection goal is set and the player must achieve it. Figure 1 shows the two screens of the game: that of the patient on the left and that of the physiotherapist on the right.

During the game, the physiotherapist can monitor the player's performance by viewing on his screen the data captured by the sensors, as well as a performance graph generated in real time. If he has chosen the "spectator" mode, his screen will be similar to the one shown in Figure 3 (right).

Additionally, he can change, at any time during the game, the minimum and maximum values of heart rate and blood oxygen saturation, the duration of the activity and the expected speed. This last configuration, in addition to allowing the personalization of the activity, also contributes to increase or decrease the difficulty of the game, thus influencing the patient's engagement. The physiotherapist simply clicks "Update" and the settings are updated for both actors.

On the other hand, the physiotherapist can also choose the "player" mode, which, in addition to all these settings, allows him to "play together with the patient", that is, pedal beside him, to increase the feeling of company and engagement. For this, the physiotherapist also receives a character similar to that of the patient player, also controllable through the keyboard. This also causes the patient's pedaling speed to be suggested by the physiotherapist's pace, as the patient realizes that he must accompany him. If the physiotherapist realizes that the patient's speed is high, he can 
decrease his own speed, which suggests to the patient that he also does it. The physiotherapist's screen with the two characters running side by side is shown in Figure 2.

During the activity, the display of the sensor data remains constant and an alert is issued if they go outside the initially stipulated range. At the end of the session, both the patient and the physiotherapist can view the final performance graph. Thus, the health professional can evaluate the patient clinically, observing the evolution of heart rate and oximetry over time of activity. These data are stored and presented to the physiotherapist in the form of a history or follow-up report, thus showing the general development of the patient throughout the sessions.

\section{CONCLUSION AND FUTURE WORK}

The complete construction of the exergame and the hardware equipment capable of capturing the data that the patient produces during the activity (adapted cycle ergometer) is completed. The game is implemented and all its features developed.

The next steps are related to evaluation and testing, with two-step planning. The first is an evaluation with specialists using the Delphi method [6], which aims, through the application of questionnaires, to collect the opinion of physiotherapy professionals on the effectiveness of the project. The second stage consists of carrying out tests with patients, which will occur with patients recovered from COVID-19 who are in motor and respiratory rehabilitation.

Finally, it is expected that, with the follow-up of this project, an alternative will be delivered to society that, by helping in telerehabilitation sessions, has a positive impact on improving patients' quality of life. We also hope that, with this project, these physiotherapy sessions with the cycle ergometer will be more fun and engaging.

\section{REFERENCES}

[1] Vinton G. Cerf. 2020. On the Internet of Medical Things. Commun. ACM 63, 8 (July 2020), 5. https://doi.org/10.1145/3406779

[2] Vitória Suyane Ferreira Cruz, Paula Thais do Nascimento Lopes, Weslla dos Santos Oliveira, Jessica Paloma Rosa Silva, and Ana Maria Braga de Oliveira. 2017. O Uso de Cartilhas Educativas como Forma de Continuidade da Educação em Saúde. Cadernos de Educação, Saúde e Fisioterapia 4 (2017), 183 - 184. http://revista.redeunida.org.br/ojs/index.php/cadernos-educacao-saude-fisioter/issue/view/32/showToc

[3] Neil M Ferguson, Daniel Laydon, Gemma Nedjati-Gilani, Natsuko Imai, Kylie Ainslie, Marc Baguelin, Sangeeta Bhatia, Adhiratha Boonyasiri, Zulma Cucunubá, Gina Cuomo-Dannenburg, Amy Dighe, Ilaria Dorigatti, Han Fu, Katy Gaythorpe, Will Green, Arran Hamlet, Wes Hinsley, Lucy C Okell, Sabine van Elsland, Hayley Thompson, Robert Verity, Erik Volz, Haowei Wang, Yuanrong Wang, Patrick GT Walker, Caroline Walters, Peter Winskill, Charles Whittaker, Christl A Donnelly, Steven Riley, and Azra C Ghani. 2020. Report 9: Impact of non-pharmaceutical interventions (NPIs) to reduce COVID-19 mortality and healthcare demand. Imperial College COVID-19 Response Team (2020), 1-20.

[4] Afonso Fleury, Davi Nakano, and José Henrique Dell Osso Cordeiro. 2014. Mapeamento da Industria Brasileira e Global de fogos Digitais. Banco Nacional de Desenvolvimento Econômico e Social (BNDES).

[5] Kirsten Jack, Sionnadh Mairi McLean, Jennifer Klaber Moffett, and Eric Gardiner. 2010. Barriers to treatment adherence in physiotherapy outpatient clinics: A systematic review. Manual Therapy 15, 3 (2010), 220 - 228. https://doi.org/10.1016/j.math.2009.12.004

[6] Walter E. Riggs. 1983. The Delphi technique: An experimental evaluation. Technological Forecasting and Social Change 23, 1 (1983), 89-94. https://doi.org/10.1016/0040-1625(83)90073-2

[7] Débora Santos and Igor Pinheiro. 2016. Telereabilitação no tratamento de disfunções neurológicas: Revisão Narrativa. Revista Scientia 1 (01 2016), 96-106.

[8] Carlos Henrique Rorato Souza, Douglas Battisti, Luciana Berretta, and Sergio Teixeira de Carvalho. 2020. Exergame com Cicloergômetro para a Reabilitação de Pacientes em Tempos de COVID-19 (Exergame with Cycle Ergometer for the Rehabilitation of Patients in Times of COVID-19). In Anais Principais do XX Simpósio Brasileiro de Computação Aplicada à Saúde (Salvador). SBC, Porto Alegre, RS, Brasil, 308-319.

[9] Marina Medici Loureiro Subtil, Dominiqui Costa Goes, Tiago Cardoso Gomes, and Mariane Lima de Souza. 2011. O relacionamento interpessoal e a adesão na fisioterapia. Fisioterapia em Movimento 24 (12 2011), 745 - 753. http://www.scielo.br/scielo.php?script=sci_arttext\&pid=S0103$51502011000400020 \&$ nrm $=$ iso 